https://dx.doi.org/10.4314/jpb.v18i3.2

Vol. 18 no. 3, pp. 182-191 (September 2021)

http://ajol.info/index.php/jpb

\section{Journal of \\ PHARMACY AND \\ BIORESOURCES}

\title{
Evaluation of knowledge, attitudes and practices of human healthcare students about antimicrobial drug use and resistance: a cross-sectional study in University of Maiduguri, Nigeria
}

\author{
Shakirat I. BELLO ${ }^{1 *}$, Fullaila O. ALIYU1, Hadiza YUSUF ${ }^{2}$, and Bello J. ALIYU² \\ ${ }^{I}$ Department of Clinical Pharmacy and Pharmacy Practice, Faculty of Pharmaceutical Sciences, University of \\ Ilorin, Ilorin. Nigeria. $\quad{ }^{2}$ Department of Clinical Pharmacy and Pharmacy Administration, Faculty of \\ Pharmacy, University of Maiduguri, Maiduguri. Nigeria.
}

Received $5^{\text {th }}$ April 2021; Accepted $3^{\text {rd }}$ August 2021

\begin{abstract}
Inappropriate consumption of antimicrobial drugs is the main cause of antibiotic resistance which is currently the most critical global public health challenge. This research aimed to evaluate knowledge, attitudes, and practices of antimicrobial drug use and resistance among 576 students. Data were collected through a questionnaire. Descriptive analyses were performed to characterize the sampled population. Ethical clearance and students' informed consent were obtained. Most of the students were within the age range of 21-25 years and have excellent knowledge of antimicrobial use. Also, most of them had very good knowledge of antimicrobial resistance. From the data analysed $445(77.3 \%)$ agreed that students should get special training on the use of antimicrobials; 120 (20.8\%) students agreed that education on the use of the antimicrobial drugs is necessary; $115(20.0 \%)$ believed that prohibiting the use of antimicrobials without a valid prescription is a solution. The knowledge level on antimicrobial drug use and resistance was excellent $329(57.1 \%)$. Most of the students' attitude as regards the usage of antimicrobials was found to be average. High rates of incorrect antimicrobial usage practices were noticed and the attitude was average. The development of an effective antimicrobial stewardship program is a necessity.
\end{abstract}

Keywords: Attitudes; Knowledge; Healthcare; Students; Antimicrobial usage

\section{INTRODUCTION}

The use of antimicrobial agents for the management of infections is increasingly challenged with the problem of antimicrobial resistance (AMR) which keeps escalating precariously in every part of the world. Antimicrobial resistance (AMR) compromises the ability to manage usual infections, leading to longer stays in health facilities, infirmity, protracted sickness, highpriced specialist care, and untimely death [1]. The incorrect use of antimicrobial drugs represents one of the main causes of antibiotic resistance. Without effective antimicrobials for the prevention and management of infections, complex surgical procedures become perilous [2]. In the healthcare facilities in Europe, the problem of resistance to

*Correspondence. E-mail: sibello10@yahoo.com Tel: +234-8035675609

ISSN 0189-8442

(cc) BY-No 2021. Published by Faculty of Pharmaceutical Sciences, University of Jos, Nigeria. Under Creative Commons Attribution-Non-Commercial 4.0 International License. https://creativecommons.org/licenses/by-nc/4.0/ 
antimicrobial agents resulted in high death rates of up to 25,000 persons yearly with an amount of approximately $€ 1.5$ billion each year [1]. United States Centers for Disease Control and Prevention showed that yearly about two million persons were inflicted with infections that are resistant to antimicrobial agents, and over twenty thousand persons were lost yearly as a consequence of these infectious diseases [3]. In Nigeria, infectious diseases accounted for about $67 \%$ of all mortality. There was increased resistance to most medications recommended for these diseases in the country [4]. A study recommended that efforts must be made in improving the rational prescription of antimicrobials among healthcare professionals in Nigeria [5]. Furthermore, the incidence of antimicrobial consumption has escalated with two in six prescriptions containing a widerspectrum antimicrobial agent [6]. The irrational use of antimicrobial agents may be attributed to dearth of knowledge on the appropriate antimicrobials consumption by the caregivers [1]. Reports from an evaluation of antimicrobial drugs use in primary healthcare institutions in India and China highlighted an unacceptably high level of errors in antimicrobial prescriptions [7]. The incidence of antimicrobial resistance is greater among the caregivers as the healthcare providers are disposed to abuse antimicrobial agents without appropriate diagnosis or advice by the pharmacist [8]. The majority of the medical and allied healthcare University students usually recommends antibacterial agents to individuals and would abruptly discontinue drug administration when the condition improved without finishing the stipulated doses [9]. There are many projects (internationally, nationally, and locally) that are striving to enhance and encourage the correct administration of antimicrobial agents. It is crucial to intensify the enlightenment of the significance of the appropriate utilization of antimicrobial drugs for normal infectious conditions among future healthcare providers [10].

On this premise, the study aim was to evaluate the knowledge, attitudes, and practices of human healthcare students of the University of Maiduguri, Nigeria about antimicrobial drug use and resistance.

\section{EXPERIMENTAL METHODS}

Study area. Borno State is geographically the largest and oldest state in the North-Eastern part of Nigeria with an estimated population of 2,596,589 in the 2005 census [11]. The state shares borders with the Republic of Niger to the North, Chad to the North-East, and Cameroon to the East. Within the country, its neighboring states are Adamawa, Yobe, and Gombe. The principal ethnic group in Maiduguri is Kanuri. Although English is the official language, Hausa and Kanuri are widely spoken. It has been the center for learning and commercial activities and full of tourist attractions [11].

Study design. This is a cross-sectional study conducted among undergraduate students of the University of Maiduguri in North-Eastern, Nigeria that were selected using simple random sampling. The study was carried out from November 2019 to February 2020.

Target population. The study population consisted of undergraduate students in the disciplines of Pharmacy, Dentistry, Medicine, Nursing, and Medical Laboratory Science.

Sample size determination. Based on the statistical formula of Fisher for a population greater than 10,000; $\alpha$-level was set at $5 \%$ with a $95 \%$ confidence interval. The Confidence interval precision was fixed at $5 \%$ and standard normal deviant at 1.96. According to the assumptions above, the sample size estimate for this study was calculated as 384 . The total number of healthcare students in the penultimate and final year in the University of Maiduguri was 1, 437 as at November, 2019. Since the population of these students was 
lower than 10,000, a statistical formula by Araoye [12] was used. This is given as

$$
\mathrm{nf}=\mathrm{n} /(1+\mathrm{n} / \mathrm{N})
$$

where $\mathrm{nf}=$ Desired sample size

$\mathrm{n}=$ Sample size for population greater than 10,000 (384);

$\mathrm{N}=$ Estimate of the study population (1437)

Therefore, 361 was obtained as the minimum sample size required. To increase the power of the study, and considering the questionnaire's non-response rate, the sample size was increased by $60 \%$, hence the number of students enrolled was 576. A proportionate quota sampling was conducted to determine the number of participants from each discipline as shown in Table 1. Medicine had the highest number, followed by nursing, pharmacy, medical laboratory science and the least was dentistry.

Eligibility criteria. Eligible for the study were medicine, dentistry, nursing, medical laboratory science, and pharmacy penultimate and final year students of the University of Maiduguri.

Instrument validation. Thorough investigations in the literature of earlier similar studies on knowledge, attitudes, and practices of human healthcare students on antimicrobial drug use and resistance were conducted. A structured questionnaire was designed and adapted to cover all the key points of the research. The validity of the content of the questionnaire was evaluated by distributing the questionnaires to sixty students recruited from same disciplines in University of Maiduguri as a pilot study for the validation process. After the pilot study, the responses from the questionnaires were analyzed with STATA 10 software package. Cronbach's alpha coefficient reliability test was used to assess the reliability and internal consistency of the items in the questionnaire. The mean of the internal consistency of the questionnaire was 0.83 . The result of the test was 0.83 , indicating the reliability of the questionnaire for the main study. The students that were involved in the pilot study were exempted from the final analysis.

Subject selection. The information on the identification number of students, study year, and discipline were obtained from the students' Affairs Office. Selection by simple random sampling was used based on their identification numbers and grouped according to discipline and study year (Medicine and Dentistry, 500-600 levels; Pharmacy, Nursing, and Medical Laboratory Science, 400-500 levels).

Data instrument. The study instrument was written in English Language and contained thirty-three closed-ended questions under four sections. The first section is the demographic section comprising of four questions that were intended to collect data on gender, age, course of study, and level of study. The second section comprised sixteen questions that evaluate students' knowledge of antimicrobial drug use. This section assessed uses of antimicrobials, factors that promote the inappropriate use of antimicrobials, consequences of antimicrobials overuse, and reliable sources to access information on the use of antimicrobials amongst others. The third section contains five questions that evaluate students' knowledge of antimicrobial resistance including the potential causes of antimicrobial resistance, the extent of agreement on the routes of spread of antimicrobial resistance, measures to control antimicrobial resistance, and others. The fourth section evaluates students' attitudes/practice about antimicrobial resistance and has eight questions, including; whether students should get special training on the rational use of antimicrobials to mitigate antimicrobial misuse/abuse during their course of study and to ascertain if they have plans to campaign on proper use of antimicrobials amongst others. Sections two and three had the options of 'agree', 'disagree' and 'do not know'. In section four, the choices include 'yes', 'no' and 'undecided'. 
Data collection. The validated selfadministered questionnaire was distributed to the students who had been preselected according to the random sample obtained from the Students Affairs Office. The validated questionnaires were distributed to the students at the end of their lecture periods. The researcher explained comprehensively to the students the objectives of the study. The students were also assured of the confidentiality of the information provided. The students who were willing to participate in the research were asked to indicate their signatures on the consent form before filling the questionnaire. Involvement in the study was made voluntary, and no benefits or incentives were offered to students.

Statistical analysis. Responses from the questionnaire were entered into a Microsoft Excel spreadsheet and rechecked for accuracy before analysis. Data analysis was done using Statistical Package for Social Sciences software version 20.0. Descriptive analyses were performed to characterize the sampled population. The results in Tables 2, 3, 4, and $5 \mathrm{~A}$ were obtained by the number of students that choose agree for each question and divided by the total number of students enrolled, likewise for those students that do not agree or do not know. For Tables 2,3,4 and 5B, the results were gotten by adding the number of students that choose to agree for all the questions under Tables 2,3,4, and 5A, and a range was set based on the highest number obtained.

Ethical consideration. The approval to conduct the research was obtained from the Ethical Committee of the University of Maiduguri with reference number: VCDNA814/Vol.64. Also, written informed consent was sought and obtained from the students before proceeding with the study. Participation of students in this work was voluntary and compensation was not granted.

\section{RESULTS}

Distribution of students by sociodemographic characteristics. The majority of the students $(69.8 \%)$ were males and 134 $(23.3 \%)$ were third-year students, the fourthyear students have the largest number $(36.6 \%)$ while the fifth and sixth-year students were $179(31.1 \%)$ and $52(9.0 \%)$ respectively. Most $(69.62 \%)$ of the students were within the age range of 21-25 years with an average age of $24.62 \pm 2.42$ years (Table 2).

Assessment of students' knowledge of antimicrobial drug use. Table 3 a shows the details of the frequency and distribution of students' responses to questions regarding antimicrobial drug use. Following the grading scale devised, the details of frequency and distribution of the students according to the knowledge of antimicrobial drug use were described in Table $3 b$.

Evaluation of students' knowledge on causes of antimicrobial resistance. Table $4 \mathrm{a}$ indicates potential causes of antimicrobial resistance as shown above. Most of the students agreed that use of antimicrobials for self-limited viral infections, poor awareness of prescribers/dispensers on antimicrobial drug resistance and lack of restrictions on antimicrobial usage among others were responsible for antimicrobial resistance.

Frequency and distribution of grading of the students 'according to the knowledge of antimicrobial resistance. Based on the scale used, the results obtained for knowledge of antimicrobial resistance among the students were shown in Table $4 \mathrm{~b}$. One third of the students had very good knowledge of antimicrobial resistance. About one fifth of these students have excellent knowledge.

Evaluation of routes of transmission of antimicrobial resistance. Table 5a described the various routes of antimicrobial resistance transmission. 
Frequency and distribution of grading of the students 'according to the knowledge of the spread of antimicrobial resistance. Table $5 \mathrm{~b}$ indicates the spread of knowledge of antimicrobial resistance. Almost one half of these student had good knowledge of spread of antimicrobial resistance and about one fifth had excellent knowledge.

Table 1: Showing the number of students required from each discipline for the study

\begin{tabular}{lccc}
\hline Serial No & Discipline & $\begin{array}{c}\text { Number of penultimate Number of } \\
\text { and final year students }\end{array}$ & $\begin{array}{c}\text { students } \\
\text { required for the study }\end{array}$ \\
\hline 1. & Medicine & 365 & 146 \\
2. & Dentistry & 71 & 29 \\
3. & Pharmacy & 330 & 132 \\
4. & Nursing & 360 & 144 \\
5. & Medical Lab Science & 311 & 125 \\
TOTAL & & 1,437 & 576 \\
\hline
\end{tabular}

Table 2: Distribution of Students by Socio-Demographic Characteristics

\begin{tabular}{|c|c|c|c|}
\hline Socio-demogra & aphic characteristics & Number of students & Percentage of students \\
\hline & Medicine & 146 & 25.3 \\
\hline & Nursing & 144 & 25.1 \\
\hline Discipline & Medical laboratory science & 125 & 21.7 \\
\hline & Pharmacy & 132 & 22.9 \\
\hline & Dentistry & 29 & 5.0 \\
\hline & Female & 174 & 30.2 \\
\hline Gender & Male & 402 & 69.8 \\
\hline & 300 Level & 134 & 23.3 \\
\hline $\mathrm{I}$ & 400 Level & 211 & 36.6 \\
\hline Lever or stuay & 500 Level & 179 & 31.1 \\
\hline & 600 Level & 52 & 9.0 \\
\hline & $\leq 20$ & 20 & 3.5 \\
\hline & $21-25$ & 401 & 69.6 \\
\hline Age (Years) & $26-30$ & 140 & 24.3 \\
\hline & $>30$ & 15 & 2.6 \\
\hline
\end{tabular}

Table 3a: Knowledge of antimicrobial drug use and spread of antimicrobial resistance

\begin{tabular}{|c|c|c|c|c|}
\hline Factors & Factors & $1 \mathrm{~N}(\%)$ & $2 \mathrm{~N}(\%)$ & $3 \mathrm{~N}(\%)$ \\
\hline \multirow{4}{*}{$\begin{array}{l}\text { Antimicrobials are used for } \\
\text { the treatment of }\end{array}$} & Bacterial Infections & $513(89.1 \%)$ & $11(1.9 \%)$ & $52(9.0 \%)$ \\
\hline & Viral Infections & $393(68.2 \%)$ & $107(18.6 \%)$ & $76(13.2)$ \\
\hline & Fungal Infections & $452(78.5 \%)$ & $77(13.4 \%)$ & $47(8.1 \%)$ \\
\hline & Protozoal Infections & $433(75.2 \%)$ & $88(15.3 \%)$ & $55(9.5 \%)$ \\
\hline \multirow{4}{*}{$\begin{array}{l}\text { Factors that may promote the } \\
\text { inappropriate use of } \\
\text { antimicrobials }\end{array}$} & Poor counseling of patients & $469(81.4 \%)$ & $64(11.1 \%)$ & $43(7.5 \%)$ \\
\hline & $\begin{array}{l}\text { Poor knowledge of } \\
\text { prescriber/ dispenser }\end{array}$ & $462(80.3 \%)$ & $74(12.8 \%)$ & $40(6.9 \%)$ \\
\hline & Patient self-medication & $470(81.6 \%)$ & $64(11.1 \%)$ & $42(7.3 \%)$ \\
\hline & Inadequate advice to patients & $453(78.6 \%)$ & $75(13.1 \%)$ & $48(8.3 \%)$ \\
\hline \multirow{4}{*}{$\begin{array}{l}\text { Consequences of } \\
\text { antimicrobials overuse }\end{array}$} & Antimicrobial resistance & $458(79.5 \%)$ & $74(12.9 \%)$ & $44(7.6 \%)$ \\
\hline & Adverse drug reactions & $326(56.6 \%)$ & $156(27.1 \%)$ & $94(16.3 \%)$ \\
\hline & Better patient outcome & $137(23.8 \%)$ & $329(57.1)$ & $110(19.1 \%)$ \\
\hline & Drug Abuse/Addiction & $311(54.0 \%)$ & $126(21.9)$ & $139(24.1 \%)$ \\
\hline \multirow{4}{*}{$\begin{array}{l}\text { Sources to access } \\
\text { information on the use of } \\
\text { antimicrobials }\end{array}$} & Lecture Notes & $275(47.7 \%)$ & $165(28.7 \%)$ & $136(23.6 \%)$ \\
\hline & Newsletters & $107(18.6 \%)$ & $351(60.9 \%)$ & $118(20.5 \%)$ \\
\hline & Official Books & $394(68.4 \%)$ & $101(17.5 \%)$ & $81(14.1 \%)$ \\
\hline & Treatment Guidelines & $445(77.3 \%)$ & $80(13.9 \%)$ & $51(8.8 \%)$ \\
\hline
\end{tabular}


Table 3b: Distribution of the students according to the knowledge of antimicrobial drug use

\begin{tabular}{lcc}
\hline Knowledge level & Number of students & Percentage of students \\
\hline Poor & 31 & 5.4 \\
Good & 109 & 18.9 \\
Very good & 107 & 18.6 \\
Excellent & 329 & 57.1 \\
Total & 576 & 100.0 \\
\hline
\end{tabular}

Table 4a: Potential Causes of Antimicrobial Resistance

\begin{tabular}{llll}
\hline Causes of Antimicrobial resistance & $1 \mathrm{~N}(\%)$ & $2 \mathrm{~N}(\%)$ & $3 \mathrm{~N}(\%)$ \\
\hline $\begin{array}{l}\text { Use of antimicrobials for self-limited viral infections } \\
\text { Use of antimicrobials with a broader than necessary spectrum despite the }\end{array}$ & $469(86.8)$ & $112(19.4)$ & $79(13.8)$ \\
$\begin{array}{l}\text { availability of susceptibility data } \\
\text { Use of antimicrobials for shorter than the standard duration }\end{array}$ & & & \\
Lack of restrictions on antimicrobial usage & $358(62.2)$ & $134(23.2)$ & $84(14.6)$ \\
Poor awareness of prescribers/Dispensers on antimicrobial drug resistance & $400(69.4)$ & $91(15.8)$ & $85(14.8)$ \\
\hline
\end{tabular}
1 = Agree; 2 = Disagree; $3=$ Do not know

Table 4b: Knowledge of antimicrobial resistance

\begin{tabular}{lcc}
\hline Knowledge level & Number of students & Percentage of students \\
\hline Poor & 127 & 22.1 \\
Good & 152 & 26.4 \\
Very good & 192 & 33.3 \\
Excellent & 105 & 18.2 \\
Total & 576 & 100.00 \\
\hline
\end{tabular}

Table 5a: Evaluation of routes of transmission of antimicrobial resistance

\begin{tabular}{|c|c|c|c|}
\hline Spread of Resistance factor & $1 \mathrm{~N}(\%)$ & $2 \mathrm{~N}(\%)$ & $3 \mathrm{~N}(\%)$ \\
\hline 1Mutation of Bacteria genes due to exposure to Antimicrobials & $352(61.1)$ & $120(20.8)$ & $104(18.1)$ \\
\hline 2Resistance organisms from healthcare facilities to the community & $376(65.3)$ & $84(14.6)$ & $116(20.1)$ \\
\hline 3Resistance spread from an infected person to another person through the ait & r 293(50.9\%) & $186(32.3 \%)$ & $97(16.8 \%)$ \\
\hline
\end{tabular}
$1=$ Agree $; 2$ = Disagree; $3=$ Do not know

Table 5b: Knowledge of the spread of antimicrobial resistance

\begin{tabular}{lcc}
\hline Knowledge level & Number of students & Percentage of students \\
\hline Poor & 206 & 35.8 \\
Good & 261 & 45.3 \\
Excellent & 109 & 18.9 \\
Total & 576 & 100.0 \\
\hline
\end{tabular}

Table 6a: Distribution of attitude of the students regarding the usage of antimicrobial drugs

\begin{tabular}{|c|c|c|c|c|}
\hline$\overline{\mathrm{S} / \mathrm{N}}$ & Measure & Yes $\mathrm{N}(\%)$ & No $\mathrm{N}(\%)$ & $\begin{array}{l}\text { Undecided } \\
\mathrm{N}(\%)\end{array}$ \\
\hline 1 & $\begin{array}{l}\text { Students should get special training on the rational use of antimicrobials to } \\
\text { mitigate antimicrobial misuse/abuse during their course of study }\end{array}$ & $445(77.3)$ & $53(9.2)$ & $78(13.5)$ \\
\hline 2 & Do you have plans to campaign on the Proper Use of Antimicrobials? & 413(71.7) & 67(11.6) & $96(16.7)$ \\
\hline 3 & Do & 393 & $84(14.6)$ & $99(17.2)$ \\
\hline & & & 274 & \\
\hline & $\begin{array}{l}\text { Do you take left-over Antimicrobials from a friend/family member/ } \\
\text { colleague because you feel their ailment is the same as yours }\end{array}$ & $/ 433(75.2)$ & $113(19.6)$ & $30(5.2)$ \\
\hline
\end{tabular}


Table 6b: Attitude of students to antimicrobial usage

\begin{tabular}{lcc}
\hline Attitude level & Number of students & Percentage of students \\
\hline Poor & 115 & 20.0 \\
Average & 373 & 64.7 \\
Excellent & 88 & 15.3 \\
Total & 576 & 100.0 \\
\hline
\end{tabular}

Table 7: Distribution of effective solutions to contain antimicrobial resistance

\begin{tabular}{llcc}
\hline & Solutions & *Frequency & Percentage \\
\hline 1 & Greater education for prescribers and dispensers on Antimicrobial Drug use & 429 & 21.2 \\
2 & Establishment of a National Antimicrobial Resistance Surveillance Service & 407 & 19.9 \\
3 & $\begin{array}{l}\text { Prohibit the use of Antimicrobials without a valid prescription } \\
4\end{array}$ & 406 & 19.9 \\
& $\begin{array}{l}\text { Good hygiene through hand washing, environmental cleaning and wearing } \\
\text { protective clothing }\end{array}$ & 402 & 19.7 \\
5 & Reduction of antimicrobial Usage for Outpatients & 397 & 19.3 \\
\hline & *otal & 2041 & 100 \\
\hline
\end{tabular}

Students' attitude/practice regarding the usage of antimicrobial drugs. Table $6 a$. shows students' attitudes regarding the usage of antimicrobial drugs.

Distribution of students' grading on attitude. The students' attitude based on score between 3-4 points in this section was described in Table 6b. Most of the students have average attitude to antimicrobial drug use.

Solutions to tackle antibiotic resistance. It was ascertained that from the responses of the students they thought antimicrobial resistance can be tackled by the various ways suggested in this study (Table 7). Most of the responses of the students was on greater education for prescribers and dispensers to mitigate antimicrobial drug resistance. This was followed by establishment of a national antimicrobial resistance surveillance service and the least was the practice of good hygiene and reduction of antimicrobial usage among outpatients.

\section{DISCUSSION}

Findings have shown that good knowledge of undergraduate healthcare students regarding issues of antimicrobial consumption and resistance could improve interventions directed at enhancing the antimicrobial use as well as the content of antimicrobial resistance [13].

In this study, it was found that most of the human healthcare students were males and within the age group of $21-25$ years with the majority of them in 400 Level. These findings coincide with previous studies on knowledge and practices in the use of antibiotics among a group of Nigerian university students [14].

In the current study, most of the students had excellent knowledge regarding antimicrobial drug use. This finding was consistent with the previous report that the knowledge of the majority of the students was adequate [15]. However, these results were inconsistent with other studies that showed moderate-poor knowledge [16]. The studies observed that this group of individuals has adequate knowledge due to the type of training received as potential healthcare providers. However, more than three-quarters of the students agree that poor counseling of patients, poor knowledge of prescriber/dispenser, patient self-medication, and inadequate advice to patients were factors that may promote the inappropriate use of antimicrobials. This is because some of the patients do not have appropriate knowledge about their disease conditions, some do not seek medical advice instead they visit quack doctors who are ignorant of the ailments while some visit patent 
medicine store for drug prescription refills. Also, some practiced self-medication based on their past experiences with previous diseases. Antimicrobial self-medication is defined as the procurement and self-consumption of the antimicrobial agent to manage an observed infectious condition [17]. This practice which has been found in both developed and low resource countries is most prominent among developing countries due to the povertystricken status of the citizens and weak health facilities [9]. Factors that could encourage selfmedication among university students have been identified as assumed knowledge of diseases and their treatments, prior experience on the use of antimicrobial agents, lack of time to visit physicians, and poor financial status [18].

The current findings revealed that irrational consumption of antimicrobial drugs may be responsible for drug resistance leading to worldwide problem as understood by majority of the participants. This agrees with previous studies conducted in Greece whereby the majority of the students affirmed that antimicrobial resistance is a global problem [19]. The most preferred sources of information on the use of antimicrobial as suggested by the students were treatment guidelines followed by the official book. Contrary to an earlier study that the most common way was text books and other guides [20].

In this study, most of the students did not practice the correct use of antimicrobial agents. Our finding is contrary to other studies among human healthcare students whereby majority of the students consulted a doctor before starting an antimicrobial drug [21]. Larger proportion of the students took left-over antimicrobials from a friend/family member/colleague. This is comparable to the studies conducted in Egypt where $75 \%$ of the students took leftover antimicrobials from a friend, family member or colleague [22]. Sharing of antimicrobial agents with persons who have related symptoms of ill-health may further promote self-medication as shown in this study. This is in keeping with a study done amongst students in Sri Lanka [23]. Possession of unused antimicrobial drugs may signify that either the amount bought or the doses prescribed were higher than the required doses. Secondly, this could be that the course of therapy was discontinued without the prescribed doses completed [1,24]. Similar studies were conducted in Ethiopia and China $[24,25]$. A study reported that pharmacists should counsel patients on the risks associated with an incomplete course of antimicrobial therapy and the practice of the use of left-over antimicrobials which is injurious [26].

To avoid antimicrobial resistance, some solutions were suggested by the students. In this study, greater education for prescribers and dispensers on antimicrobial drug use was ranked first among other suggested solutions. This was to create awareness targeting the medical professional, prescribers, and pharmacists regarding the rules and laws of antimicrobial prescription and standard treatment guidelines that should be followed [27]. The establishment of a national antimicrobial resistance surveillance service is also suggested which will monitor the use of antimicrobial in the country. This can help in combating antimicrobial resistance. The control of antimicrobial resistance cannot be addressed by medical professionals and scientists alone [1]. Continuous education is essential to enable healthcare providers to learn the need for rational prescription practices and the importance of evidencebased prescription. Also, the general population and other stakeholders have a central role to play. Furthermore, a study conducted reveals that the government should consider antimicrobial resistance as a public health priority issue [2].

Conclusion. This study has demonstrated that human healthcare students at the University of Maiduguri have excellent knowledge of 
antimicrobial use and resistance. Despite the excellent knowledge, high rates of incorrect antimicrobial usage practices were observed. These findings warrant the development of an effective and comprehensive antimicrobial stewardship program in undergraduate education.

Acknowledgement. The authors appreciate the respondents for the time spent in filling the questionnaires.

\section{REFERENCES}

1. World Health Organization (WHO), 2020. Antimicrobial resistance: Does stopping a course of antibiotics early lead to antibiotic resistance? Available at https://www.who.int/news-room/q-adetail/antimicrobial-resistance-does-stopping-acourse-of-antibiotics-early-lead-to-antibioticresistance. Accessed on 11/3/2021.

2. Ayukekbong, JA, Ntemgwa M and Atabe AN (2019); The threat of antimicrobial resistance in developing countries: causes and control strategies, BioMed Central, 6(47):1-8.

3. Dadgostar P(2019); Antimicrobial Resistance: Implications and Costs, Infection and Drug Resistance, 12:3903-3910. doi: 10.2147/IDR.S234610.

4. Federal Ministry of Health, (FMoH) (2017). 'Antimicrobial Use and Resistance in Nigeria. Situation Analysis and Recommendations. https://ncdc.gov.ng/themes/common/docs/protocols/ 56_1510840387.pdf. Cied on 01/03/2021.

5. Chukwu, EE., Oladele, DA, Enwuru, CA Gogwan, PL., Abuh, D, Audu, RA and Ogunsola, FT 2021) 'Antimicrobial resistance awareness and antibiotic prescribing behavior among healthcare workers in Nigeria: a national survey, BMC Infectious Diseases, 21, 22. https://doi.org/10.1186/s12879-020-05689-X

6. Abubakar, U. (2020) 'Antibiotic use among hospitalized patients in northern Nigeria: a multicenter point-prevalence survey'. BMC Infectious Diseases, 20(86). https://doi.org/10.1186/s12879-020-4815-4.

7. Sulis, G, Daniels, B, Kwan, A, Gandra, S, Daftary, A. Das, J and Pai, M (2020). 'Antibiotic overuse in the primary health care setting: a secondary data analysis of standardised patient studies from India, China and Kenya, BMJ Global Health, 5. doi:10.1136/bmjgh2020-003393.
8. Manderson, L. (2020). 'Prescribing, care and resistance: antibiotic use in urban South Africa'. Humanities and Social Sciences Communications, 7(77), pp. https://doi.org/10.1057/s41599-02000564-1

9. Ajibola, O, Omisakin, OA, Eze, AA. and Omoleke, SA. (2018) 'Self-Medication with antibiotics, attitude and knowledge of antibiotic resistance among community residents and undergraduate students in NorthwestNigeria, Diseases, 6(2):32.doi: 10.3390/dis eases6020032.

10. Torumkuney, D., Nica, M., Nistor, I., Vatcheva

Dobrevska, R., Petrovic, V., Stoica, A., Hanicar, B., Antic, D.J. and Morrissey, I. (2018) 'Results from the Survey of Antibiotic Resistance (SOAR) 2014-16 in Bulgaria. Romania. Serbia and Croatia'. Journal of Antimicrobial Chemotherapy, 73(8):2275. doi:10.1093/ jac/dky219.

11. Bukar, H. (2018)'Predominant tribes in Maiduguri and the commonly used languages, history and religion' Encyclopaedia Britannica 7(43):65-78.

12. Araoye, M.O (2004) 'Research Methodology with Statistics for Health and Social Sciences ( $1^{\text {st }}$ edition) (pp.115-120). Ilorin, Nigeria: Nathadex Publishers.

13. Wall, S. (2019) 'Prevention of antibiotic resistance - an epidemiological scoping review to identify research categories and knowledge gaps, Global Health Action, 12(1):1-27.

14. Byrne, M.K.., Miellet, S., McGlinn, A., Fish. J., Meedya, S., Reynolds, N. and van Oijen, A.M. (2019). 'The drivers of antibiotic use and misuse:the development and investigation of a theory driven community measure. BMC Public Health, 19(1425): https://doi.org/10.1186/s12889-019-77968

15. Dutt, H., Sarkhil, M., Abdul, M. and Singh, G. (2018) 'A comparative knowledge, attitude, and practice study of antimicrobial use, self-medication and antimicrobial resistance among final year students of MBBS, BDS, and BSc Nursing at a tertiary care hospital at Kannur'. Journal of Physiology Pharmacy and Pharmacology. 8(9):13051311. doi:10.5455/ njppp.2018.8.0518130052018.

16. Sakr, S., Ghaddar, A., Hamam, B. and Sheet, I. (2020) 'Antibiotic use and resistance: an unprecedented assessment of university students' knowledge, attitude and practices (KAP) in Lebanon, BMC Public Health, 20(535), pp. https://doi.org/10.1186/s12889-020-08676-8

17. Esan, DT. Fasoro, A.A, Odesanya, O.E, Esan, T.O., Ojo, E.F. and Faeji, CO (2018) 'Assessment 
of self-medication practices and its associated factors among undergraduates of a private University in Nigeria'. Journal of Environmental and Public Health, (7): https://doi.org/10.1155/2018/5439079.

18. Soroush, A, Abdi, A, Andayeshgar, B, Vahdat, A. and Khatony, A. (2018). 'Exploring the perceived factors that affect self-medication among nursing students: a qualitative study'. BMC Nursing, 17(35) pp. doi.org/10.1186/s12912-018-0302-2.

19. Efthymiou, P., Gkentzi, D. and Dimitriou, G. (2020). 'Knowledge, attitudes and perceptions of medical students on antimicrobial stewardship, Antibiotics, 9(821), pp. doi:10.3390/antibiotics9110821www.mdpi.com/jour nal/antibiotics.

20. Yang, K, Wu, D and Tan, F (2016) 'Attitudes and perceptions regarding antimicrobial use and resistance among medical students in Central China' Springer Plus,_5(1):1779.

21. Asogwa, E, Offor, SJ and Mbagwu, HOC (2017) 'Knowledge, attitude and practice towards antibiotics use among non-medical University students in Uyo, Nigeria, Ifunanya Journal of Advances in Medical and Pharmaceutical Sciences, 15(1):1-11.

22. Tahoon, M.A., Khalil, M.M., Hammad, E. Morad, WS Mohammed awad S and Ezzat S (2020). The effect of educational intervention on healthcare providers' knowledge, attitude, \& practice towards antimicrobial stewardship program at, National
Liver Institute, Egypt. Egypt Liver Journal 10(5) https://doi.org/10.1186/s43066-019-0016-5

23. Jayaweerasingham, M, Angulmaduwa, $S$ and Liyanapathirana, V (2019) 'Knowledge, beliefs and practices on antibiotic use and resistance among a group of trainee nurses in Sri Lanka'. BMC Research Notes, 12:601 https://doi.org/10.1186/s13104-019-4640-2.

24. Sun, C, Hu, YJ, Wang, X, Lu, J, Lin, L and Zhou, X. (2019) 'Influence of leftover antibiotics on selfmedication with antibiotics for children: a crosssectional study from three Chinese provinces' $B M J$ Open, 9, pp. doi:10.1136/bmjopen-2019-033679.

25. Kassahun, H. and Tesfaye, D. (2020). 'Disposal practices of unused medications among patients in public health centers of Dessie town, Northeast Ethiopia: A Cross Sectional Survey'. Integrated Pharmacy Research and Practice, 9:65-70.

26. Atif, M, Asghar, S, Mushtaq, I, Malik, I., Amin, A., Babar, Z. and Scahill,S. (2019). 'What drives inappropriate use of antibiotics? A mixed methods study from Bahawalpur, Pakistan. Infectious Drug Resistance, 12:687-699.

27. Bennie, M, Malcolm, W, Marwick, CA, Kavanagh, K, Sneddon, J, and Nathwani, D. (2017). 'Building a national infection intelligence platform to improve antimicrobial stewardship and drive better patient outcomes: the Scottish experience', Journal of Antimicrobial Chemotherapy, 72(10):29382942. 